\title{
Cloud Computing and Energy Efficiency: Mapping the Thematic Structure of Research
}

\author{
Andrzej Lis ${ }^{1, *(\mathbb{D}}$, Agata Sudolska ${ }^{2, *(\mathbb{D}}$, Ilona Pietryka ${ }^{3}$ and Adam Kozakiewicz ${ }^{4}$ \\ 1 Department of Business Excellence, Faculty of Economic Sciences and Management, Nicolaus Copernicus \\ University, 87-100 Torun, Poland \\ 2 Department of Enterprise Management, Faculty of Economic Sciences and Management, Nicolaus \\ Copernicus University, 87-100 Torun, Poland \\ 3 Department of Economics, Faculty of Economic Sciences and Management, Nicolaus Copernicus University, \\ 87-100 Toruń, Poland; ilonapietryka@umk.pl \\ 4 Research and Academic Computer Network-National Research Institute, 01-045 Warsaw, Poland; \\ adam.kozakiewicz@nask.pl \\ * Correspondence: andrzejlis@econ.umk.pl (A.L.); aga@econ.umk.pl (A.S.); \\ Tel.: +48-56-6114887 (A.L.); +48-56-6114890 (A.S.)
}

Received: 14 June 2020; Accepted: 6 August 2020; Published: 9 August 2020

\begin{abstract}
The dynamic growth in the use of cloud computing systems results in increasing energy consumption. Consequently, more and more attention is given to energy efficiency issues both in research and theory development as well as the business practice of cloud computing systems. In spite of the rapid development of research, the field has not been mapped from the bibliometric perspective yet. This study aims at publication profiling and mapping the thematic structure of the cloud computing energy efficiency research field. Detailed research objectives include: (1) profiling scientific publications in the field, (2) identifying and exploring thematic research areas, (3) identifying emerging topics and discussing their potential as future research lines. The aforementioned objectives are translated into the following study questions: (1) What are the most productive nations, institutions, source titles, and scholars contributing to research on energy efficiency in cloud computing? (2) What does the thematic structure of the research field look like? (3) What are the "hot" research topics attracting scholars' attention? The research methodology toolbox includes a combination of bibliometric descriptive studies (research profiling), science mapping (keyword co-occurrence analysis), and literature reviews (systematic literature review). Bibliometric data for analysis were elicited from the Scopus database. The VOSviewer software supported bibliometric analysis and data visualization.
\end{abstract}

Keywords: cloud computing; energy efficiency; bibliometrics; co-word analysis; keywords co-occurrence analysis; Scopus; VOSviewer

\section{Introduction}

Cloud computing seems to be one of the leading lines of development taken by information and communication technology in the second decade of this century. Growing internet coverage and new wireless data transmission technologies allow end devices to be virtually always online, making new kinds of services possible. The ubiquity of computing devices, especially mobile ones, coupled with the growth of digital society communicating over social networks increases the role of cloud-hosted services as a more versatile alternative to classic local applications tied to one computer. This new paradigm of information processing raises significant power consumption issues on both ends of the system-growing data centers consume vast amounts of energy, giving strong economic and 
environmental motivation for research on ways to reduce consumption, while mobile devices require effective energy management to extend battery life.

The issue of energy efficiency in cloud computing systems-which, as a relatively new field of scientific inquiry, emerged a decade ago - has been receiving more and more attention in academia. This research interest translates into an increasing number of publications. As of 20 May 2020, in the Scopus database we found 307 documents for the title search including the logical combination of phrases "cloud computing" AND "energ*" AND "efficien*". We used the truncation (stemming) technique, i.e. entering the truncation symbol (in this case an asterisk) after the root of a word, in order to include into the search the forms of a word with various endings. The topic search (i.e., searching in titles, keywords, and abstracts) for the same query resulted in 4669 publications. In spite of the rapid development of research, the field has not been mapped from the bibliometric perspective yet. Among the aforementioned queries, we found no bibliometric records including the phrases "bibliometric*" OR "scientometric*" OR "informetric*" in their titles, keywords, and abstracts. Searching in the Web of Science Core Collection database, we received the same negative result. Taking into account that bibliometric methodologies are successfully used to map the research field focused on cloud computing in general [1-10] or some of its detailed aspects—such as, e.g., the risks and uncertainties related to cloud computing [11], cloud computing security [12], cloud computing in the healthcare sector [13], or cloud computing and customer quality of experience [14]—-we identified a need for a bibliometric study exploring scientific production dealing with energy efficiency in cloud computing systems.

The study aims at publication profiling and mapping the thematic structure of the cloud computing energy efficiency research field. The detailed research objectives include: (1) profiling scientific publications in the field, (2) identifying and exploring thematic research areas, (3) identifying emerging topics and discussing their potential as future research lines. The aforementioned objectives are translated into the following study questions: (1) What are the most productive nations, institutions, source titles, and scholars contributing to research on energy efficiency in cloud computing? (2) What does the thematic structure of the research field look like? (3) What are the "hot" research topics attracting scholars' attention?

The remainder of this study consists of three main sections explaining methodology, presenting research findings, and discussing the findings. Firstly, the process of research sampling for bibliometric data and the employed methods are explained. Secondly, the research productivity is profiled, and the thematic structure of the research field and emerging topics are identified. Thirdly, these findings are analyzed and discussed, with a focus on the development potential of the research field and possible avenues for further research.

This study offers readers a comprehensive review of the literature presenting the panorama of research on energy efficiency in cloud computing. It identifies the leading stakeholders in the field and offers opportunities to find out core references as well as potential collaborators and source titles to disseminate research findings. Through mapping thematic areas and emerging topics, this study enables the reader to better understand the conceptual structure of the research field. Employing bibliometric methodology, based on strict scientific rigor, is a feature distinguishing this study from other narrative or systematic literature reviews.

\section{Materials and Methods}

\subsection{Materials}

We chose the Scopus database as a source of bibliometric data for analysis. Scopus, together with the Web of Science Core Collections, are considered as leading collections of quality literature [15-17]. We searched for the following combination of phrases: title search ("cloud computing" AND "energ*" AND "efficien*'"). We used the truncation technique (stemming) in order to retrieve all the words, including any endings of the given root words. We restricted the scope of search to the titles of publications to focus on the works referring directly to the issue of energy efficiency in cloud computing 
systems. No limitations regarding the date of publication or a subject area were imposed, in order to embrace all relevant publications. As of 20 May 2020, in total we retrieved 307 items, comprising mainly conference papers $(145 ; 47.2 \%)$ and journal articles $(139 ; 45.3 \%)$. Nearly all of them are written in English (304, 99.0\%). Detailed characteristics of the research sample structure are presented in Table 1.

Table 1. Research sample structure.

\begin{tabular}{cc}
\hline Category & Items (Number of Publications) \\
\hline $\begin{array}{c}\text { Types of Documents } \\
\text { Language }\end{array}$ & Conference Paper (145); Article (139); Book Chapter (15); Review (5); Book (1) Editorial (1); Erratum (1) \\
English (304); Chinese (3)
\end{tabular}

\subsection{Methods}

In general, scientific outputs in research fields are analyzed with the use of literature reviews [18] and/or bibliometric methods [19-21]. Literature reviews, ranging from narrative reviews to systematic reviews and quantitative meta-analysis studies [22,23], are the most widespread approach to explore amassing production in a research field. Literature reviews, which are usually qualitative, show a great potential for deep and thorough analysis. Nevertheless, they are often focused on a micro-perspective of several publications and lack a macro-perspective aimed at discovering research themes and trends in a large body of literature. Thus, it is recommended to supplement traditional literature reviews with a quantitative approach represented by bibliometric methodology $[19,21]$. The following types of bibliometric methods are recommended for exploring a research field: descriptive studies, such as research profiling [19] or science mapping methods, including citation analysis, co-citation analysis, bibliographic coupling, co-author analysis, and co-word analysis [20,21].

Following an ambidextrous approach to methodology, we combine bibliometric methods and literature reviews in order to exploit their synergies and ensure an appropriate level of research triangulation. Firstly, research profiling [19] supports the analysis of scientific production distribution in the field and identification of leading contributors. We employ general publication profiling, which together with subject area profiling and topic profiling constitute the research profiling framework $[9,24,25]$. The aim of general publication profiling is to recognize the most productive countries, research institutions, source titles, and authors conducting research on energy efficiency in cloud computing. The method of general publication profiling allows for portraying the research context and understanding the structure of the research community cultivating the field. Secondly, a co-word analysis [26], based on keyword co-occurrence, is applied to map the clusters of high-frequency keywords manifesting leading thematic areas in the field and the keywords of the latest average date of publication representing emerging topics of scientific inquiry. Co-word analysis shows a high potential for mapping the cognitive structure of the field [27]. Therefore, we use it to replace a traditional topic profiling focused on identifying leading topics in a field from the perspective of source titles, authors, subject areas, and core references $[9,24,25]$, with science mapping displaying leading thematic areas and relationships among them and their components, as well as "hot" emerging topics. We employ VOSviewer [28,29] science mapping software to support our keyword co-occurrence analysis and visualize its findings. Recently, VOSviewer has been more and more often used in bibliometric analyses. As of 12 June 2020, in the Scopus database there are 614 indexed publications which contain the phrase "VOSviewer" within titles, keywords, and abstracts, 480 of which were issued in the period 2018-2020. The publications included in the research sample provide 1965 keywords, among which 1459 are reported only once. Therefore, following Donohue [30], cited in Guo D. and associates [31], we calculated the minimum number of occurrences $(\mathrm{N}=10)$ for the keywords to be recognized as high-frequency keywords and to be included into further co-occurrence analysis. We found 54 expressions meeting these minimum requirements. For the purposes of comparing and contrasting the changes in the research field, we selected the sub-sample comprising the publications 
issued in 2009-2015 ( $\mathrm{N}=128$ ), which provide 965 keywords (among which 693 occurred only once). The characteristics of VOSviewer and the values of its parameters employed in the analysis are enumerated in Table 2.

Table 2. VOSviewer settings.

\begin{tabular}{|c|c|}
\hline Item & Characteristic/Value \\
\hline Type of analysis & Co-occurrence analysis \\
\hline Unit of analysis & All keywords \\
\hline Counting method & Full counting \\
\hline Method of normalization of strength of the links between items & Association strength method \\
\hline Layout & - \\
\hline Attraction & 2 (default setting) \\
\hline Repulsion & 0 (default setting) \\
\hline Clustering & - \\
\hline Resolution (detail of clustering) & 1 (default setting) \\
\hline Minimum number of keywords in a cluster & 1 (default setting) \\
\hline Function of merging small clusters & Switched on \\
\hline Visualization & - \\
\hline Scale & $\begin{array}{l}\text { network and overlay visualization-1.00 } \\
\text { item density visualization- } 1.20\end{array}$ \\
\hline Weights & occurrences \\
\hline Labels size variation & $\begin{array}{l}\text { network and overlay visualization- }-0.00 \\
\text { item density visualization- }-0.50\end{array}$ \\
\hline Maximum number of lines & 1000 \\
\hline Number of analyzed high frequency keywords & $\begin{array}{l}\text { main sample (2009-2020)-54 } \\
2015 \text { sub-sample (2009-2015)-40 }\end{array}$ \\
\hline $\begin{array}{c}\text { Minimum number of occurrences to include a keyword in } \\
\text { analysis }\end{array}$ & $\begin{array}{l}\text { main sample }(2009-2020)-10 \\
2015 \text { sub-sample }(2009-2015)-7\end{array}$ \\
\hline
\end{tabular}

Source: authors' own study. Data sourced from VOSviewer (20 May 2020).

Thirdly, the methodology of systematic literature review $[18,23,32]$ was employed in order to explore the status of research within each of the identified thematic clusters and support the discussion of the findings from the bibliometric analysis. Among the 307 publications comprising the research sample, we excluded 13 items (duplicates, unavailable works, non-relevant records). In total, 294 publications were included for further analysis. In the analysis process, we split them into two groups categorized by the date of publication (2009-2015 and 2016-2020). The details of the sampling process are displayed in Table 3. The reference list of publications selected for analysis and the key research findings are available in the Supplementary Materials.

Table 3. Research sampling for the systematic literature review (number of publications).

\begin{tabular}{cccc}
\hline & 2009-2015 & 2016-2020 & Total \\
\hline Retrieved records & 128 & 179 & 307 \\
Excluded records & & & \\
duplicates & 6 & 4 & 10 \\
unavailable records & 2 & 0 & 2 \\
non-relevant records & 0 & 1 & 1 \\
Analyzed records & 120 & 174 & 294 \\
\hline Source: authors' own study. Data sourced from Scopus (20 May 2020).
\end{tabular}

With high-frequency keywords assigned to the clusters, relevant works referring to the thematic areas were identified. For this purpose, we selected the top 10 publications with the highest number of received citations in each cluster and then verified whether they were included in other clusters. In total, the 15 most influential publications were analyzed. 


\section{Results}

\subsection{Research Productivity and General Publication Profiling}

The publications constituting the sample cover the period from to 2009 to 2020. Since 2009, when the research field emerged, until 2016, the number of publications issued per year increased to above 50 items. Then, in 2017-2018 a decline to the level of around 30-35 publications was noticed. The research productivity recovered in 2019, when 52 publications were reported, equaling the peak of 2016. In 2020, as of May 20, 10 records were indexed in Scopus. Thus, employing simple extrapolation, in total 31 publications could be expected by the end of the year. The graphical representation of productivity of research is displayed in Figure 1. The number of citations received by the publications comprising the research sample was constantly increasing between 2010 and 2019 from 6 to 1697 (cf. Figure 2). The rapidly increasing number of received citations may be explained by the development of the research field, manifested in the growing number of publications. On the one hand, more scientific production means more potential publications to refer to, on the other hand usually each publication produces citations in its literature review section and a discussion section. Thus, the increasing cumulated number of publications in the field, in spite of fluctuations in the yearly scientific output (cf. Figure 1), results in a continuous growth of the number of citations received by research on energy efficiency in cloud computing (cf. Figure 2).

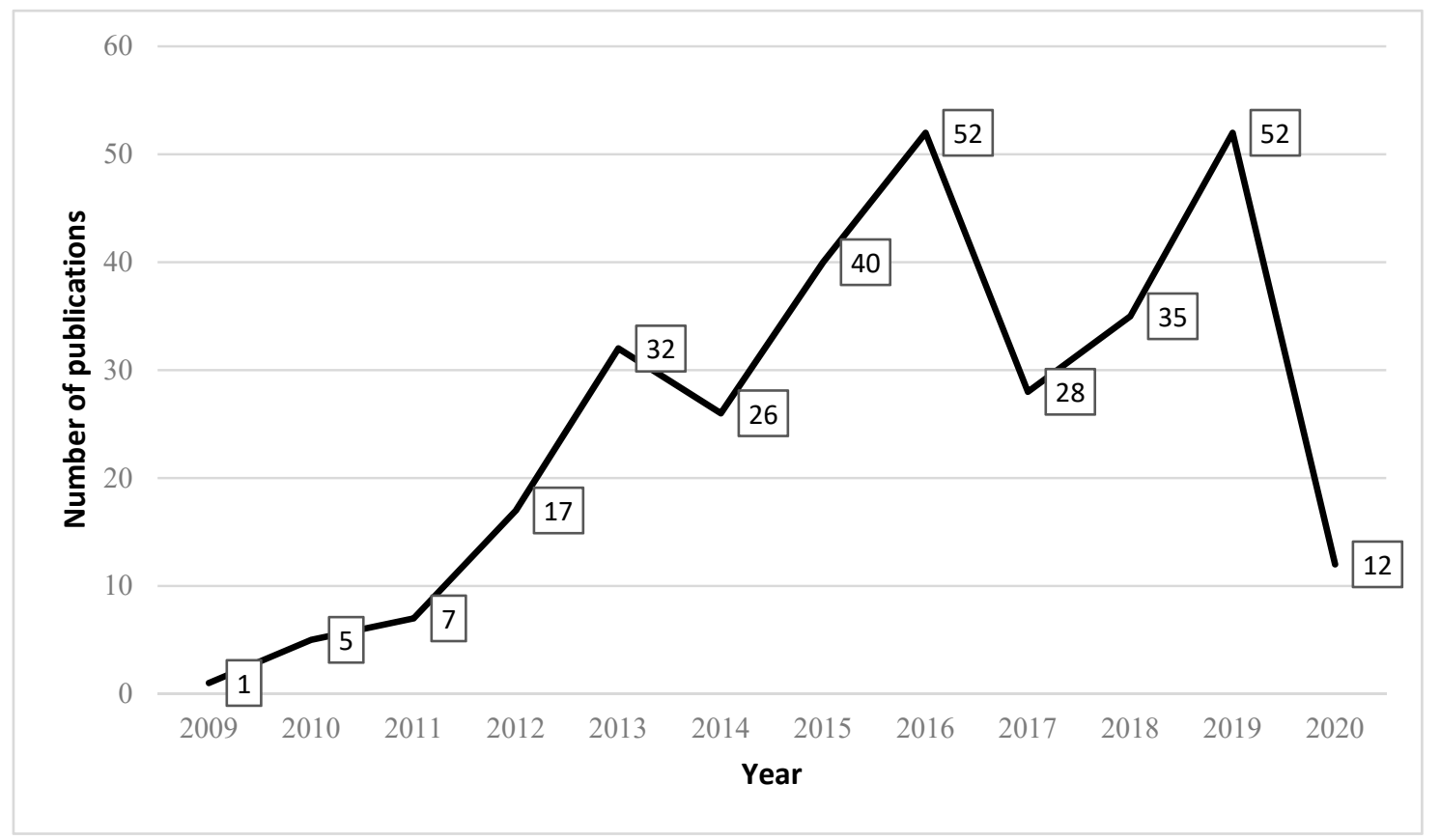

Figure 1. Number of publications in research on energy efficiency in cloud computing (2009-2020). Source: authors' own study. Data sourced from Scopus (20 May 2020). 


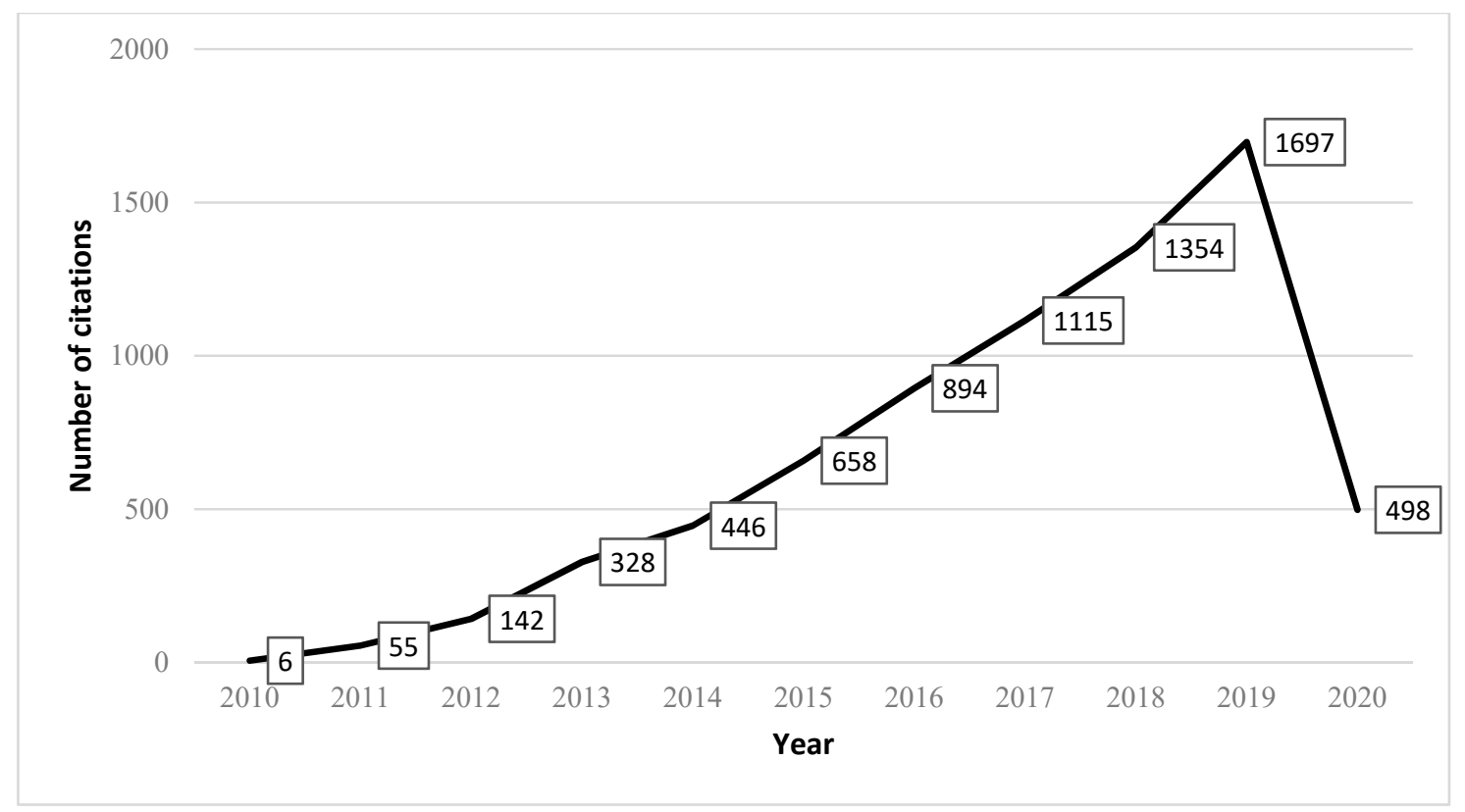

Figure 2. Number of citations received by research on energy efficiency in cloud computing (2009-2020).

Source: authors' own study. Data sourced from Scopus (20 May 2020).

The output of research on energy efficiency in cloud computing systems is distributed over 19 non-exclusive subject areas defined by Scopus. The most populated of them are: computer science (261 publications), engineering (108), and mathematics (60). Asian and Anglo-Saxon nations are the most active actors in conducting research within the field. China (with 84 publications) and India (82) are the leaders. The next contributors are: the United States, Canada, Australia, and the United Kingdom, as well as South Korea and Iran. Two continental European nations (Italy and France) supplement the list of the most productive countries in researching on energy efficiency in cloud computing systems. Chinese Tsinghua University, with eight publications, is found to be the leading contributor among research institutions. Among the top 12 universities, which contributed to the research field with at least five publications, there are institutions from China (4), Australia (3), Canada (1), Iran (1), Luxembourg (1), Singapore (1), and the United States (1). "Advances in Intelligent Systems and Computing", "IEEE Access", and "Future Generation Computer Systems" are recognized as the source titles which attract most of the scholars' attention as platforms to communicate their findings from research on energy efficiency aspects in cloud computing systems. The most prolific authors are: Pascal Bouvry, affiliated with the University of Luxembourg, and Samme Ullah Khan, from North Dakota State University, the United States. Other leading contributors represent institutions from Luxembourg, Australia, and Singapore. The most cited core references are: the study on principles of managing energy efficient cloud computing and policies for allocating resources for such systems by Beloglazov et al. [33], the review of methods and technologies for energy consumption optimization in computing by Berl et al. [34], the "survey of energy-efficient data centers and cloud computing systems" by Beloglazov et al. [35], as well as the presentation of heuristics aimed at saving consumption of energy in cloud computing by Lee and Zomaya [36]. The detailed data regarding subject areas within the cloud computing energy efficiency research field and the most productive contributors including such categories as: country, research institution, source title, and researcher, and the most cited core references are provided in Table 4. 
Table 4. General publication profiling of research on cloud computing energy efficiency.

\begin{tabular}{cc}
\hline Category & Top Items \\
\hline $\begin{array}{c}\text { Subject Areas (Number of } \\
\text { Publications) }\end{array}$ & $\begin{array}{c}\text { Computer Science (261); Engineering (108); Mathematics (60); Material Science (13); Decision Sciences } \\
\text { (12); Energy (10); Physics and Astronomy (10); Social Sciences (10); Business, Management and } \\
\text { Accounting (9); Environmental Science (7); Medicine (4); Multidisciplinary (4); Biochemistry, Genetics } \\
\text { and Molecular Biology (2); Economics, Econometrics and Finance (2); Pharmacology, Toxicology and } \\
\text { Pharmaceutics (2); Agricultural and Biological Sciences (1); Chemical Engineering (1); Chemistry (1); } \\
\text { Earth and Planetary Sciences (1); Undefined (1) }\end{array}$ \\
\hline $\begin{array}{c}\text { Most Productive Countries } \\
\text { (Number of Publications } \geq 8)\end{array}$ & China (84); India (82); United States (31); Canada (20); Australia (19); United Kingdom (18); South \\
Korea (16); Italy (15), Iran (10); France (8)
\end{tabular}

\subsection{Leading Thematic Areas}

Among 1965 keywords mentioned in the publications comprising the research sample, those with the highest number of occurrences are: "energy efficiency" (247), "cloud computing" (229), "energy utilization" (158), "green computing" (90), "energy efficient" (75), and "mobile cloud computing" (72). The prominence of high-frequency keywords in the cloud computing energy efficiency research field is visualized in Figure 3. In order to observe changes in research interests manifested in publications issued between 2009 and 2020, in Table 5 we compared the top 10 high-frequency keywords (ranked by the number of occurrences) in the middle of the period covered in the analysis (including publications issued in 2009-2015) at its end (encompassing the whole analyzed timeframe-i.e., 2009-2020). The year 2015 was selected as a reference point for a comparison and contrast analysis by the subjective decision of the authors. Our motivation was to split the whole analyzed period in the middle and maintain a balanced distribution of the number of publications (those issued in 2009-2015 make up 42\% of the whole research sample).

Comparing and contrasting the top high-frequency keywords in the middle of the period covered by the analysis (2015) and at its end (2020), the stability of research interests in the research field is visible. The majority of expressions with the highest number of occurrences is included in both lists. Nevertheless, two topics are noticed, which joined the top 10 list. Firstly, "virtual machines" in 2015 ranked 13th (with 16 occurrences) and climbed up to the 10th position. Secondly, an even more spectacular increase in prominence was achieved by "green computing". In 2015, this expression (with 15 occurrences) was ranked 14th. In 2020, "green computing" was found to be the fourth most frequent keyword in research on energy efficiency issues in the context of cloud computing systems.

All the 54 high-frequency keywords taken for analysis were categorized into thematic clusters with the use of the network visualization function of VOSviewer (Figure 4). The map shows the relationships among the clusters and the items belonging to them. The distance between the items corresponds to their relatedness-i.e., the shorter the distance between the two items, the more relatedness between them is noticed [29]. 


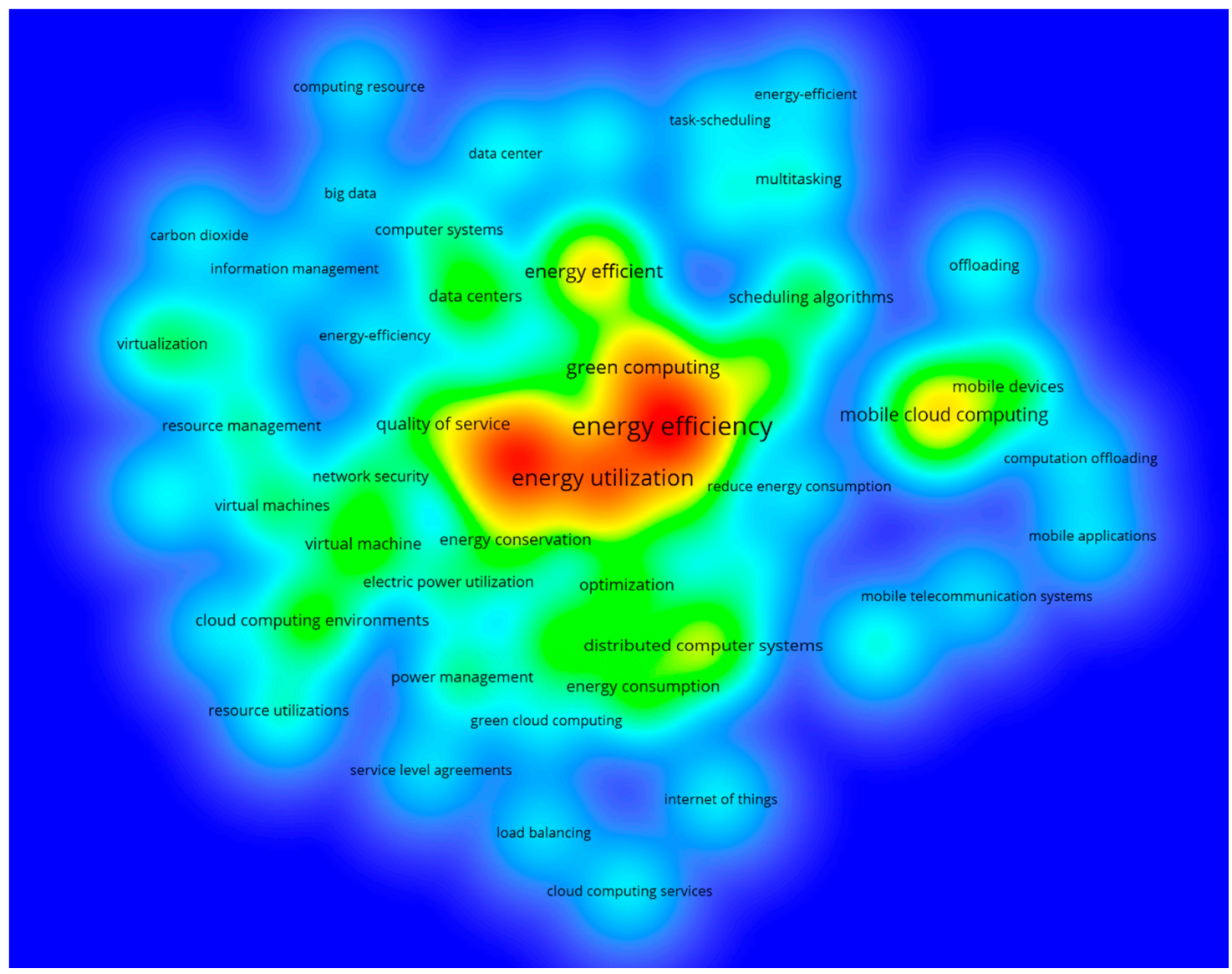

Figure 3. High-frequency keywords in research on cloud computing energy efficiency. Source: authors' own study. Data sourced from Scopus, analyzed with VOSviewer (20 May 2020).

Table 5. High-frequency keywords in research on cloud computing energy efficiency.

\begin{tabular}{ccccc}
\hline \multirow{2}{*}{ Rank } & \multicolumn{2}{c}{ 2009-2015 } & \multicolumn{2}{c}{$\mathbf{2 0 0 9 - 2 0 2 0}$} \\
\cline { 2 - 5 } & Keywords & Number of Occurrences & Keywords & Number of Occurrences \\
\hline 1. & energy efficiency & 106 & energy efficiency & 247 \\
2. & cloud computing & 98 & cloud computing & 229 \\
3. & energy utilization & 70 & energy utilization & 158 \\
4. & energy efficient & 38 & green computing & 90 \\
5. & mobile cloud computing & 27 & energy efficient & 75 \\
6. & distributed computer systems & 24 & mobile cloud computing & 72 \\
7. & data centers & 23 & distributed computer systems & 49 \\
8. & scheduling & 21 & scheduling & 47 \\
9. & quality of service & 19 & quality of service & 41 \\
10. & mobile devices & 19 & virtual machines & 37 \\
\end{tabular}

Source: authors' own study. Data sourced from Scopus, analyzed with VOSviewer (20 May 2020). 


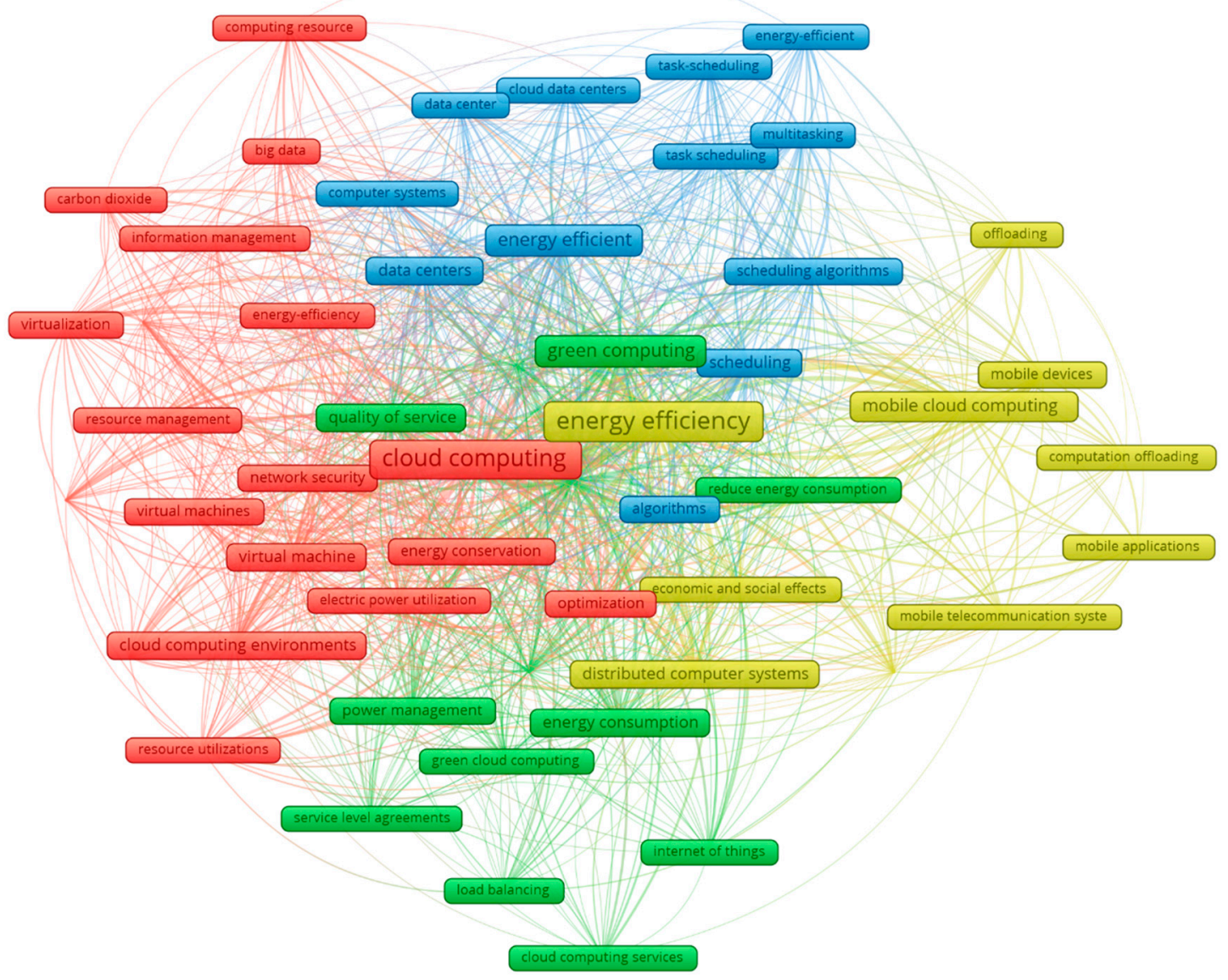

Figure 4. Thematic clusters in research on cloud computing energy efficiency. Source: authors' own study. Data sourced from Scopus, analyzed with VOSviewer (20 May 2020).

The detailed list of expressions categorized into each of the thematic clusters as well as the bibliometric data describing each item are presented in Table 6 . The high-frequency keywords with the greatest prominence in the field are bolded.

All the identified clusters include many generic keywords related to the topics of power efficiency and minimizing the environmental impact of data centers. However, a different thematic focus can be noticed in each case, allowing us to assign simple labels to the clusters. Cluster 1 is especially generic, including such seemingly unrelated topics as network security, Java programming language, and carbon dioxide. Its defining trait is that those topics seem to be considered mainly in the context of virtual machines. Therefore, we label this cluster "virtualization". Cluster 2 highlights the power management as a central theme, with most of the keywords including the words "green", "power'", or "energy". This issue is discussed in various contexts, such as digital storage, the internet of things, the quality of service, and load balancing. Thus, the label "power" seems to be fitting in this case. Cluster 3 deals with the issues of the efficient handling of tasks in a data center, specifically discussing scheduling algorithms, convincing us to label this cluster as "scheduling". Cluster 4 concentrates on the issue of offloading tasks from mobile devices to the cloud in an energy-efficient fashion, hence it was labeled as "offloading". In summary, a network analysis of high-frequency keywords indicates the four following thematic clusters within the research field focused on the studies of energy efficiency in cloud computing systems: (1) virtualization, (2) power, (3) scheduling, and (4) offloading.

We employed the technique of core references and research topics profiling, one of the components of the research profiling method $[19,24]$, to identify the most influential pieces of writing within the identified clusters (Table 7) to be analyzed through the systematic literature review. 
Table 6. Structure of thematic clusters in research on cloud computing energy efficiency.

\begin{tabular}{|c|c|c|}
\hline Cluster Number/Label/Color & $\begin{array}{l}\text { Items (Number } \\
\text { of Keywords) }\end{array}$ & Keywords (Occurrences; Links; Total Link Strength) \\
\hline $\mathrm{C} 1 /$ virtualization/red & 18 & $\begin{array}{l}\text { big data }(10,31,70) \text {; carbon dioxide }(12,24,73) \text {; cloud computing }(229,53,1296) ; \\
\text { cloud computing environments }(34 ; 43 ; 244) \text {; computing resource }(10,24,61) ; \\
\text { electric power utilization }(19,47,141) \text {; energy conservation }(33,46,227) ; \\
\text { energy-efficiency }(11,28,63) ; \text { information management }(10,28,73) ; \text { Java } \\
\text { programming language }(14,28,106) ; \text { network security }(20,41,165) ; \text { optimization } \\
\text { (32, 45, 235); resource management }(18,36,127) \text {; resource utilizations }(17,31,120) ; \\
\text { virtual machine }(37,48,305) \text {; virtual machine placements }(11,30,95) ; \text { virtual } \\
\text { machines }(23,39,172) \text {, virtualization }(24,37,150) \text {; virtualizations }(13,37,107)\end{array}$ \\
\hline C2/power/green & 13 & 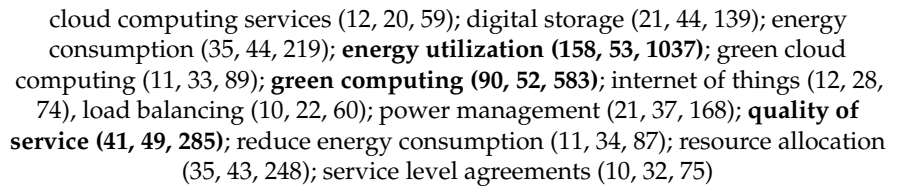 \\
\hline C3/scheduling/blue & 12 & $\begin{array}{c}\text { algorithms }(26,43,180) \text {; cloud data centers }(13,28,89) \text {; computer systems }(18,34, \\
\text { 104); data center }(14,37,101) \text {; data centers }(37,48,254) \text {; energy efficient }(75,51 \text {, } \\
\text { 460); energy-efficient }(10,27,80) \text {; multitasking }(15,37,142) ; \text { scheduling }(\mathbf{4 7}, \mathbf{4 8}, \\
\text { 356); scheduling algorithms }(27,45,245) ; \text { task scheduling }(13,36,103) ; \\
\text { task-scheduling }(11,34,109)\end{array}$ \\
\hline C4/offloading/yellow & 10 & $\begin{array}{l}\text { computation offloading }(10,14,46) \text {; distributed computer systems }(\mathbf{4 9}, \mathbf{4 8}, \mathbf{3 0 8}) ; \\
\text { economic and social effects }(13,38,102) \text {; energy efficiency }(247,53,1424) ; \\
\text { energy-efficient scheduling }(16,31,121) \text {; mobile applications }(10,17,62) ; \text { mobile } \\
\text { cloud computing }(72,41,358) ; \text { mobile devices }(31,32,189) ; \text { mobile } \\
\text { telecommunication systems }(10,25,77) ; \text { offloading }(15,20,69)\end{array}$ \\
\hline
\end{tabular}

Source: authors' own study. Data sourced from Scopus, analyzed with VOSviewer (20 May 2020).

Table 7. Core references in the thematic clusters in research on cloud computing energy efficiency.

\begin{tabular}{ccccccc}
\hline \multirow{2}{*}{ Publications } & \multirow{2}{*}{ Number of Citations } & \multicolumn{5}{c}{ Rank } \\
\cline { 3 - 7 } & & Total & Cluster 1 & Cluster 2 & Cluster 3 & Cluster 4 \\
\hline Beloglazov et al., 2012 [33] & 1627 & 1 & 1 & 1 & 1 & 1 \\
Berl et al., 2010 [34] & 439 & 2 & 2 & 2 & 2 & 2 \\
Beloglazov et al., 2011 [35] & 410 & 3 & - & - & - & - \\
Lee and Zomaya, 2012 [36] & 365 & 4 & 3 & 3 & 3 & 3 \\
Miettinen and Nurminen, 2010 [37] & 277 & 5 & - & - & 4 & 4 \\
You et al., 2016 [38] & 167 & 6 & 4 & 4 & - & 5 \\
Mastelic et al., 2015 [39] & 142 & 7 & 5 & - & 5 & 6 \\
Hameed et al., 2016 [40] & 139 & 8 & 6 & 5 & - & 7 \\
Guo S. et al., 2016 [41], & 131 & 9 & 7 & 6 & 6 & 8 \\
Mi et al., 2010 [42] & 119 & 10 & 8 & 7 & 7 & - \\
Boru et al., 2015 [43] & 117 & 11 & 9 & 8 & - & 9 \\
Zhang et al., 2013 [44] & 108 & 12 & - & - & - & 10 \\
Goudarzi and Pedram, 2012 [45] & 93 & 13 & 10 & 9 & 8 & 11 \\
Kaur and Chana, 2015 [46] & 91 & 14 & 11 & 10 & 9 & 12 \\
Li et al., 2016 [47] & 77 & 18 & 15 & 13 & 10 & 77 \\
\hline
\end{tabular}

Source: authors' own study. Data sourced from Scopus (20 May 2020).

Within the research field regarding cloud computing energy efficiency, the works that are the most cited ones include the publications of: Beloglazov et al. [33], Berl et al. [34], Beloglazov et al. [35], Lee and Zomaya [36], and Miettinen and Nurminen [37]. During the research process, we selected the 10 most cited works in each cluster. Subsequently, we searched all the clusters in order to detect if the identified most cited publications occur in the remaining clusters. As the study by Beloglazov et al. [35] does not provide any keywords, it is not included in any of thematic clusters categorized with the method of keyword co-occurrence analysis.

Cluster 1, labeled as "virtualization", encompasses the core references that are the most cited in the whole research area-i.e., Beloglazov et al. [33], Berl et al. [34], Lee and Zomaya [36], and You et al. [38]. Beloglazov et al. [33] provide a definition for an architectural framework and principles in relation to energy-efficient cloud computing. They present energy-aware resource provisioning and allocation algorithms. Specifically, they propose energy-aware allocation heuristics that provision data 
center resources for customer applications in order to improve the data centers' energy efficiency but at the same time provide the negotiated quality of service. The results obtained indicate that the cloud computing model has a huge potential due to the fact that it affords significant cost savings but on the other hand reveals a high potential in terms of the energy efficiency improvement under dynamic workload scenarios. Berl et al. [34] discuss various methods and technologies that are applied for the energy-efficient operation of computer hardware and network infrastructure. Taking into account the current best practice and the relevant literature sources in the field, the aforementioned authors point out the key research challenges that come about while the discussed energy-saving techniques are put into cloud computing environments. Lee and Zomaya [36] introduce two energy-conscious task consolidation heuristics oriented to maximize resource utilization. The proposed heuristics allocate each task to a particular resource on which the energy consumption for performing the task is explicitly or implicitly reduced without the task execution depletion. Based on experimental results, the aforementioned authors prove that the proposed heuristics exhibit promising energy-saving capability. You et al. [38] demonstrate a new solution that combines two technologies, which are mobile cloud computing and microwave power transfer, in order to allow computation in passive low-complexity devices such as sensors or wearable computing devices. A simulation performed by the researchers shows the achievability of wirelessly powered mobile cloud computing, as well as obtaining its optimal control.

Cluster 2, marked as the "power", shares the most cited core references with Cluster $1[33,34,36,38]$. Among other papers, Hameed et al. [40] try to pinpoint open challenges related to energy-efficient resource allocation. In their publication, they lay the existing hardware and software-based techniques accessible for this out. Resting on the energy-efficient research dimension taxonomy, they summarize the available techniques already presented in the literature. Finally, they analyze the advantages as well as disadvantages of the extant techniques facing the offered research dimension taxonomy, namely: resource adaption policy, objective function, allocation method, allocation operation, and interoperability. Guo et al. [41] provide an energy-efficient dynamic offloading and resource scheduling (eDors) approach that is aimed at diminishing energy consumption as well as cutting down the time for application completion. The results of their research in a real testbed indicate the capacity of the eDors algorithm to effectively reduce the energy-efficiency cost by adjusting the CPU clock frequency of smart mobile devices in an optimal way drawn on the dynamic voltage and frequency scaling technique in local computing, and adapting the transmission power for wireless channel conditions in cloud computing. Mi et al. [42] introduce an online self-reconfiguration solution regarding reallocating virtual machines in large-scale data centers. The results of extensive experiments indicate that the approach proposed by the aforesaid authors enables one to effectively switch off more unnecessary running physical machines as against the existing approaches without downgrading the performance of the whole system. Boru et al. [43] investigate the issue referring to data replication in cloud computing data centers, considering both the energy efficiency and bandwidth consumption of the system. The results of their research received from a mathematical model as well as from the extensive simulations, allow one to disclose the trade-offs in terms of performance and energy efficiency. Additionally, these results enable the designing of future data replication solutions.

"Scheduling" is a wide subject of discussion in the publications included in Cluster 3 . The majority of core references included in Cluster 3 are also covered by Clusters 1 and $2[33,34,36,41,42]$. The next most frequently cited article is the work by Miettinen and Nurminen [37]. The aforementioned authors investigate the critical factors that impact the energy consumption of mobile clients in cloud computing. They discuss the measurements regarding the central characteristics of current mobile handheld devices that define the basic balance between local and remote computing. Moreover, they present a particular example in order to evidence the energy savings. The results obtained by the authors indicate that the trade-offs are tremendously sensitive to the precise workload characteristics and data communication patterns, as well as the applied technologies. Finally, they debate the implications of their research in relation to the design and engineering of energy-efficient mobile cloud computing 
solutions. Mastelic et al. [39] present an extensive analysis of the infrastructure that supports the cloud computing paradigm with regards to energy efficiency. In their work, the authors offer a systematic study focused on analyzing the energy efficiency of most important data center domains, covering server and network equipment as well as cloud management systems and appliances, comprising the software employed by end users. Next, they apply their approach to examine the relevant scientific and industrial literature regarding the state-of-the-art practices in data centers and their equipment. They also draw out the extant challenges and propose future research avenues in the field. Goudarzi and Pedram [45] solve the issue related to the placement of energy-efficient virtual machines in a cloud computing system. They offer a solution which first creates multiple copies of virtual machines and then uses dynamic programming and local searching to put these copies in the physical servers. The algorithm proposed by Goudarzi and Pedram [45] minimizes the total energy consumption by up to $20 \%$. Kaur and Chana [46] highlight the need for energy efficiency and discuss the dual role of cloud computing. On the one hand, they highlight cloud computing's contribution to the increase in energy consumption, and on the other hand they focus on cloud computing treated as a method enabling a reduction in energy wastage. The aforementioned authors' review presents energy efficiency techniques in cloud computing and provides taxonomies for the classification and evaluation of the existing studies.

The leading core references of Cluster 4, labeled as "offloading", are encompassed also by other clusters $[33,34,36-41,43,45,46]$. Among the publications that are not shared with other clusters, Zhang et al. [44] investigate the problem of energy conservation for executing mobile applications by task offloading to the cloud. The task scheduling problem was formulated as a constrained stochastic shortest path problem over an acyclic graph. To obtain the task scheduling policy for the Markovian chain model, they applied the Lagrangian relaxation-based aggregated cost (LARAC)algorithm. The results recommend a one-climb policy that includes at most onetime migration from the mobile device to the cloud. Moreover, the authors argue that collaborative execution allows a significant reduction in the energy consumption of a mobile device. Li et al. [47] develop a dynamic energy-efficient virtual machine migration and consolidation algorithm based on a multi-resource energy-efficient model. The proposed algorithm minimizes the active physical nodes number as well as reduces the amount of virtual machine migrations. Moreover, it demonstrates a better energy efficiency in data centers for cloud computing.

\subsection{Emerging Topics}

We identified the emerging topics within the cloud computing energy efficiency research field with the use of the overlay visualization function of VOSviewer (Figure 5). In the map, colors display an average date of publication of the keywords taken for analysis. The colors range from blue (the oldest average date of publication), through green and yellow, to red (the newest average date of publication) $[29,48]$. The list of the keywords characterized by the most up-to-date average date of publication is provided in Table 8.

As the analysis shows, many research topics remained active during the decade, even if the popularity of relevant keywords changed (e.g., "energy-efficient scheduling" in the first period corresponds to "task scheduling" in the second one). However, three major emerging topics can be identified.

The first emerging research topic identified in the sample is the impact of IoT on the cloud infrastructure. While mobile computing - a concept related in many ways-has already been a vital research area in the first half of the decade, the "internet of things" has only entered the list of top ten keywords in the second period, with a fairly recent average date of publication. The importance of this topic is exemplified by the fact that, among the top five most highly cited papers from the period 2016-2020, three explicitly discuss mobile and IoT topics. You et al. [38] specifically address passive, low-complexity devices such as sensors or wearable computing devices. Guo et al. [41], as well as Kandavel and Kumaravel [49], discuss energy-efficient computation offloading from smart mobile 
devices and mobile gadgets, respectively. In contrast, among the top five most-cited publications from the previous period, only the fifth one is related to this topic-Miettinen and Nurminen [37] discuss the consumption of energy by mobile handheld devices and the way the type of workload affects whether local computation or offloading to the cloud is more energy-efficient.

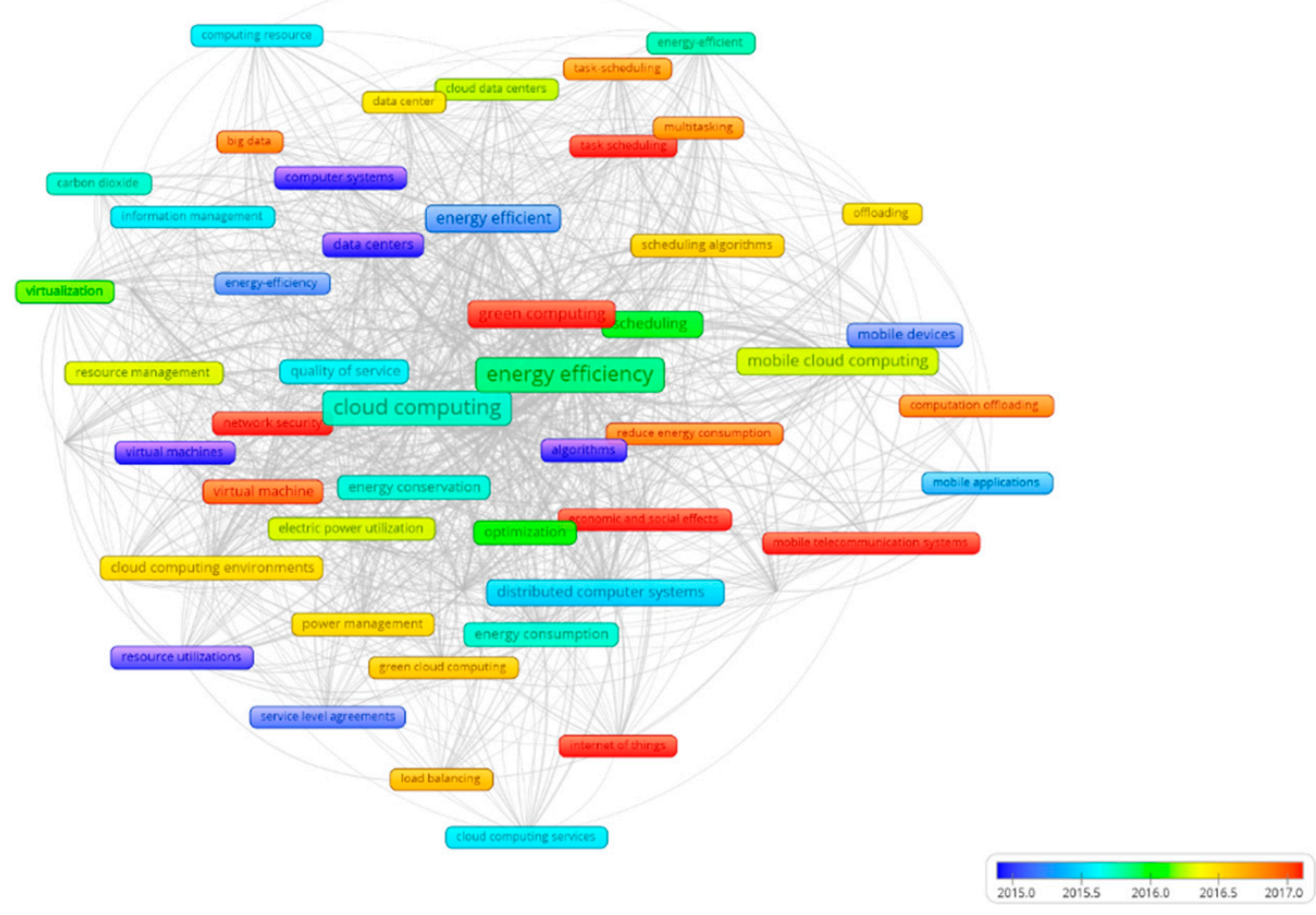

Figure 5. Average date of publication of high-frequency keywords in research on cloud computing energy efficiency. Source: authors' own study. Data sourced from Scopus, analyzed with VOSviewer (20 May 2020).

Table 8. The most up-to-date high-frequency keywords in research on cloud computing energy efficiency.

\begin{tabular}{|c|c|c|c|c|}
\hline \multirow{2}{*}{ Rank } & \multicolumn{2}{|l|}{ 2009-2015 } & \multicolumn{2}{|l|}{ 2009-2020 } \\
\hline & Keywords & ADP & Keywords & ADP \\
\hline 1. & Java programming language & 2014.62 & network security & 2017.90 \\
\hline 2. & mobile applications & 2014.43 & task scheduling & 2017.69 \\
\hline 3. & data center & 2014.43 & green computing & 2017.50 \\
\hline 4. & digital storage & 2014.36 & internet of things & 2017.42 \\
\hline 5. & energy-efficient scheduling & 2014.30 & economic and social effects & 2017.08 \\
\hline 6. & distributed computer systems & 2014.21 & mobile telecommunication systems & 2017.00 \\
\hline 7. & algorithms & 2014.11 & virtual machines & 2016.89 \\
\hline 8. & cloud computing environments & 2014.09 & reduce energy consumption & 2016.82 \\
\hline 9. & mobile cloud computing & 2014.00 & big data & 2016.80 \\
\hline 10. & mobile devices & 2013.95 & computation offloading & 2016.80 \\
\hline
\end{tabular}

Source: authors' own study. Data sourced from Scopus, analyzed with VOSviewer (20 May 2020).

Secondly, only in the recent years has the relationship between network security and energy efficiency been seriously considered in the papers included in our sample. This is clearly a very recent phenomenon, as in the sample only two papers published in 2015 and no earlier ones include security in their key findings at all. Joyee De et al. [50] discuss user-selected security policies and their impact on energy consumption, while Afianian et al. [51] focus on the key management aspects of outsourcing data. In contrast, in the later period "network security" is among top high-frequency keywords, with the latest average date of publication (see Table 7). The papers from this period discuss 
various aspects of security, either as a side topic or as the core of the research. Ahamed et al. [52], the most highly cited paper from this group, discuss security-based selection and placement algorithms employing compartment isolation, while showing that this focus on security does not negatively impact power consumption in the data center.

Finally, the third emerging topic is the economic and social effects of energy-efficient cloud computing. This topic is different in its nature, as it is rarely at the core of the research findings of the articles-instead, this topic increasingly appears as an additional keyword, as economic and social effects are discussed in otherwise purely technical publications. Among the highly cited papers with a high focus on this aspect is the work of Malekloo et al. [53], which explicitly mentions the importance of service level agreement (SLA) and quality of service (QoS) factors and proposes a multi-objective approach to virtual machine placement, which is aware of energy and QoS.

\section{Discussion}

\subsection{General Trends}

In regard to research field profiling, the significant role of China and India among the most productive countries should be noticed. This tendency is consistent with the general trend in the publication output and citation distribution over the last decade, as illustrated, e.g., in [54,55]. Note that, in this specific research area, the increase in the output and quality of results may be driven not only by the general trend, but also by the rapid development of new data centers in those countries and growing environmental problems, increasing the local applicability of research results and thus providing motivation-and funding - to research teams. Another reason for the significant role of China and India as the leading countries in regard to the number of produced publications may refer to the fact that, in general, these countries are not burdened with investments in traditional IT systems, so they rapidly develop cloud computing technologies. According to a 451 Group (a technology research American group) report, the market of cloud computing services in these two Asian nations is expected to increase three times and reach a level of over $\$ 2.4 \mathrm{bn}$ by the end of 2020. The 451 Group assumes that China and India will become the most influential cloud players in the Asia-Pacific area, producing, respectively, revenues of over $\$ 1.59 \mathrm{bn}$ and $\$ 851 \mathrm{~m}$ through 2020 (https://451research.com/).

In regard to research interests, dynamic growth in research concerning green computing has been observed in recent years. This correlates to the general trend promoting environmentally friendly technology. In terms of energy consumption, this illustrates a visible change in the way energy efficiency is seen-no longer as just an issue of economy, where power consumption is a cost worth reducing, but also as an issue of ecological responsibility. In computing, this shift may have been strengthened by the discussions resulting from the dynamic growth of electronic currency. E-coins based on proof-of-work, such as the original BitCoin, create a significant demand for computing power, which is arguably not used for conventionally productive purposes, but still consumes energy. Since the global energy consumption of electronic currency mining is now estimated to be on the scale of a medium-sized state (see, e.g., de Vries [56]) and the problem of proof-of-work costs extends to many applications of blockchain, energy efficiency becomes a pressing issue.

\subsection{Comparison to Other Reviews}

As already mentioned in the Introduction section, we found no bibliometric studies mapping research on energy efficiency in cloud computing. Nevertheless, in order to compare our findings with other publications analyzing research production in the field, we additionally scanned literature reviews. As of 12 July 2020, we searched for the conjunction of phrases ("cloud computing" AND "energ*" AND "efficien*") in titles of publications AND ("review") in their titles, keywords and abstracts. Among the 12 publications retrieved from Scopus, we removed duplicates and some less relevant papers, and finally analyzed seven literature reviews. Comparing and contrasting our findings with those reviews, some differences in the aims and methodology approaches should be 
highlighted. Firstly, while our study aims at mapping thematic areas of scientific inquiry in the research field, all the analyzed publications employ the literature review methodology to explore some particular aspects related to managing energy efficiency in cloud computing. For instance, Berl et al. [34] study energy efficient solutions used in IT systems and challenges to implement them in the context of cloud computing. Sharma and colleagues $[57,58]$ provide comprehensive reviews focused on the issues of reliability and energy efficiency, as well as the trade-offs between them in cloud computing. Choudhary et al. [59] explore the techniques optimizing energy efficiency for virtual machine placement in cloud computing data centers. Atiewi et al. [60] provide a review of "energy-efficient task scheduling algorithms in cloud computing". Usman et al. [61] revise the "nature-inspired techniques" used to improve energy efficiency in cloud computing data centers. Mondal et al. [62] analyze job scheduling algorithms contributing to energy savings and lowering emissions of carbon dioxide. Secondly, the analyzed publications employ the method of narrative literature review, which, contrary to systematic literature review, is often criticized for a lower level of scientific rigor, subjectivity, and biases [18,32]. Thus, our study combining the rigorous methodologies of co-word analysis and systematic literature review seems to offer a very comprehensive and reliable analysis of the research field status.

\subsection{Remarks on the Method}

The results of the analysis support the value of a mixed approach, combining research profiling, keyword analysis, and systematic literature reviews. The clusters identified in the keyword analysis (Section 3.2) are relatively easy to name based on high-frequency keywords alone; however, the review of papers in each cluster revealed that the thematic focus of the cluster need not be clearly linked to that label. While this could be expected in regard to generic cluster 1 ( $\mathrm{C} 1 /$ virtualization/red), the remaining labels would seem rather well supported by large numbers of closely related keywords-however, only in case of the cluster 4 (C4/offloading/light blue), the most-cited works are indeed rather clearly related to the task offloading from mobile devices, as the label suggests. However, it seems that the works in each cluster are indeed related thematically, meaning that the grouping we found based on keywords is correlated to the actual contents of the papers. Keyword frequency analysis is also effective in identifying trends in secondary topics. A good illustration is the emerging topic "economic and social effects" - as discussed above, it is not often at the core of the publications in the analyzed sample and would not be identified based on the title and abstract analysis alone. However, its importance has indeed grown, and new papers increasingly include a discussion of this aspect of the research they present.

Another interesting observation can be made on the risks of using the number of publications as a sole measure of a researcher's impact on a given field. As an example, consider the two most prolific authors found in the study, who have co-authored a total of 11 papers in the sample (three of those co-authored by both of them). Their significant impact is clear, as the best cited of those papers has the 11th best number of citations in the sample (117), and the best they both co-authored has 63 citations, the 22nd best result (note that the results may be slightly skewed by the fact that self-citations are included and most of their papers have many authors). Their papers taken together have 375 citations, over $5 \%$ of the total number of citations in the sample. The authors are not first authors of any of those papers; their average place in the list of authors is approximately 3.3. The numbers above are rather impressive. On the other hand, however, consider Anton Beloglazov from the University of Melbourne, Australia, the author of only two papers in our sample [33,35], in both cases as the first author. These two papers take the first and third place in the ranking of most cited papers, with a total of 2037 citations-a staggering $28.2 \%$ of the total number of citations in the sample. The second one alone has 410 citations-more than all the papers of the two most productive authors combined.

Comparing the impact of those authors on the analyzed research field is clearly not possible based on bibliometric parameters alone-a deep knowledge of the field and a review of their papers is necessary. Clearly, while bibliometric approaches are effective in drawing the line between the leaders 
in the field and sporadic co-authors with little impact, they may not be useful as a tool for ranking the top researchers. Additionally, when assessing the impact of a researcher with those methods, one should not focus on just one parameter, as the problem is naturally multicriterial and heavily blurred by issues such as publication language or journal popularity. The volume and quality of output are separate, and one should always remember that, while reputable journals and events provide some lower bound on the quality of the published material, the higher bound might not even exist-a groundbreaking paper redefining the field may be authored by researchers who do not write much and rarely in English.

\subsection{Recommended Lines of Future Research}

The emerging topics identified in the previous section are not surprising, and at the same time can be considered as related in the wider context. The last decade saw the mainstream emergence and rapid growth of the internet of things. The growing capabilities of smartphones and a growing amount of smart gadgets available on the market have heavily changed the workload handled in the cloud. More and more, data from customer devices and computation offloaded from them became central to the role played by the data centers, which still needed to remain energy-efficient, even though the workload was no longer dominated by large computing tasks and data storage. The things themselves are also often battery-powered, so energy efficiency on the client end is obviously crucial. This is a significant reason for the growing frequency of the "internet of things" keyword in the recent publications. Another reason for its growing popularity is the growing deployment of IoT in the datacenters as tools for better energy efficiency, as discussed, e.g., by Liu et al. [63]. The impact of IoT on cloud computing and the resulting challenges for future work are discussed at length by Gill et al. [64]. Due to the rapid growth of the internet of things, the impact of IoT on the cloud infrastructure can be considered as the first of the identified lines of future research related to energy efficiency in cloud computing.

The rapid growth of IoT resulted in a large number of companies with relatively low experience in software-driven products entering the market with their smart devices-with a lot of functionality anchored in cloud-side computation. The lacking security of the new solutions has been repeatedly pointed out by security experts, but largely ignored by the industry, until high-visibility incidents of exploitation by malicious actors in the last years of the decade—such as the Mirai botnet (e.g., Antonakakis et al. [65])—have underlined the need for the secure design and implementation of such devices. As a result, IoT security is nowadays considered as one of the most urgent problems in cybersecurity research around the world (confirmed, e.g., by the EUNITY project workshops comparing European and Japanese cybersecurity research landscapes [66,67]). As IoT and mobile devices are usually heavily supported by cloud computing due to limited power and computing resources, a significant amount of papers in our sample can indeed be expected to consider network security and IoT.

This focus on security in a mobile or things context is also strengthened by the privacy issues of these technologies. Offloading processing to the cloud, or perhaps even more importantly storing the backup of data from consumer devices, including contacts, private photos, and communication in the cloud, provides a completely new challenge to cloud infrastructures. The data they now need to handle may be very sensitive, while at the same time the individual users cannot be expected to follow best practices in protecting their vulnerable information in the way companies can. Among others, these issues are discussed by Itani et al. [68], who propose an approach applying incremental cryptography and trusted computing concepts in order to develop solutions proving better protection to data entrusted by customers, lowering consumption of energy and providing support for data operations. The privacy issues of the analyzed technologies are highly significant due to the fact that potential leaks of data not only result in very negative PR for the service providers, but also severe legal liability-the second half of the decade has seen a significant increase in the legal protection of personally identifiable information (e.g., the General Data Protection Regulation in Europe or the recent updates to the Japanese Act on the Protection of Personal Information). This is another contributing factor to the 
growing amount of security-related papers in the sample. The above aspects of security and privacy in the context of energy-efficient clouds and mobile systems are a major current and future research direction. Interesting surveys covering this area have been provided by Mollah et al. [69] and Stergiou at al. [70]. Taking into account the aforementioned argumentation, we find the relationship between network security and energy efficiency as the second of the recommended lines of future research on energy efficiency in cloud computing.

The new role of the cloud in the life of an average smartphone user also affects the rising frequency of the "economic and social effects" keyword in the observed publications. However, this effect should not be overestimated, as the review of the sample clearly shows that the main focus in this area is still on the economic side, basically verifying what effect the advances in energy efficient data center management have on its ability to provide SLA and QoS guarantees. Reaching beyond the sample, multidisciplinary research regarding the economic and social aspects of green computing is active and promising in the near future. For example, Radu [71] discusses the factors-both pragmatic and ethical-influencing the decisions to implement green computing in organizations, while the respective roles of social movements and corporations in implementing green practices is discussed by Carberry et al. [72]. Conducting this type of research in the specific context of the energy-efficient cloud seems to be the third promising line of future work.

\section{Conclusions}

Summing up, the study provides responses to the three research questions: (1) What are the most productive nations, institutions, source titles, and scholars contributing to research on energy efficiency in cloud computing? (2) What does the thematic structure of the research field look like? (3) What are the "hot" research topics attracting scholars' attention? Referring to the first research question, general publication profiling points out the following features of research on energy efficiency in cloud computing: (1) the majority of scientific production is categorized under such subject areas as: computer science, engineering, and mathematics; (2) Asian and Anglo-Saxon nations are the main contributors to research within the field, while China and India are the unquestioned leaders in regard to the number of publications; (3) Chinese Tsinghua University is recognized as the most prolific research institution; (4) "Advances in Intelligent Systems and Computing", "IEEE Access" and "Future Generation Computer Systems" are among the source titles which attract the most of the scholars' attention as the platforms to communicate their findings; (5) the most prolific authors in the field are: Pascal Bouvry, affiliated with the University of Luxembourg, and Samme Ullah Khan from North Dakota State University, the United States. In regard to the second research question, the network analysis of high-frequency keywords indicates the four following thematic clusters within the research field focused on the studies of energy efficiency in cloud computing systems: (1) virtualization, (2) power, (3) scheduling, and (4) offloading. In response to the third research question, the analysis of the average date of publication for high-frequency keywords identifies the following emerging topics constituting potential future lines of research: (1) the impact of IoT on the cloud infrastructure, (2) the relationship between network security and energy efficiency, and (3) the economic and social effects of energy-efficient cloud computing.

The contribution of our study is first and foremost important from the perspective of further research in the field. In regard to research profiling, the study findings may be useful for existing and prospective scholars cultivating research on energy efficiency in cloud computing. Finding the most prolific institutions and researchers provides to other scholars' information about potential research partners. Discovering the leading source titles indicates the most relevant platforms to disseminate research findings in the community. Exploring core references highlights the publications which are the most valued and cited by other scholars and categorizes their findings within thematic clusters in the field. So far, there has not been found any bibliometric study mapping the scientific output of research on energy efficiency in cloud computing. Thus, discovering main thematic areas and new, 
"hot" topics through bibliometric study brings new quality to discussing the research status of the field, its development, and lines of further research.

Analyzing and discussing findings, the research process limitations should be taken into account. Firstly, although Scopus is a valued database of quality peer-reviewed publications, some partiality may result from using only one source of data. For instance, Scopus shows preferences for publications written in English. In our study, nearly all the publications from the research sample were written in English. Thus, employing other sources of bibliometric data to replicate the study is recommended as one of the future lines of research. Secondly, in the research sampling process, we employed the title search-i.e., we included only publications comprising selected expressions in their titles. Such an operation was conducted purposely in order to focus on publications directly referring to the issue of energy efficiency in cloud computing systems. Nevertheless, some other valuable works could have been excluded as showing weaker relatedness to the topic of the study. Thus, in the future, it seems to be interesting to enlarge the research sample to compare and contrast the findings from such a study with our results. Thirdly, some inherent weaknesses of the co-word analysis need to be mentioned, such as neglecting publications without keywords, lacking control of assigning keywords in the indexation process, omitting some less frequent expressions, or differentiating between various linguistic forms of similar or even the same expressions.

Supplementary Materials: Table S1: Reference list and key research findings (2009-2015); Table S2: Reference list and key research findings (2016-2020) are available at http://www.mdpi.com/1996-1073/13/16/4117/s1.

Author Contributions: Conceptualization, A.L.; methodology, A.L.; data retrieval, A.L.; research profiling analysis, A.L.; keywords co-occurrence analysis, A.L., systematic literature analysis, A.S. and I.P.; discussion, A.K.; writing-original draft preparation, A.L., A.S., I.P. and A.K.; writing-review and editing, A.L., and A.S.; visualization, A.L.; supplementary materials, A.S. and I.P.; supervision, A.L.; project administration, A.L., A.S.; funding acquisition, A.L. and I.P. All authors have read and agreed to the published version of the manuscript.

Funding: This research was funded with statutory research budget by the Faculty of Economic Sciences and Management, Nicolaus Copernicus University in Toruń, Poland.

Conflicts of Interest: The authors declare no conflict of interest. The funders had no role in the design of the study; in the collection, analysis, or interpretation of data; in the writing of the manuscript; or in the decision to publish the results.

\section{References}

1. $\mathrm{Wu}, \mathrm{J}$.; Chen, Q. Mapping the emerging field of cloud computing: Insights from a visualization analysis. In Proceedings of the IEEE International Conference on Systems, Man and Cybernetics, Seoul, Korea, 14-17 October 2012; pp. 1794-1799.

2. Heilig, L. A view on cloud computing from above the clouds. Computer (Long Beach Calif.) 2014, 47, 6926707. [CrossRef]

3. Heilig, L.; Vob, S. A scientometric analysis of cloud computing literature. IEEE Trans. Cloud Comput. 2014, 2, 266-278. [CrossRef]

4. Ma, F.; Zhan, N. Study on global cloud computing research trend. In Proceedings of the Fifth International Conference on Graphic and Image Processing (ICGIP 2013); SPIE: Washington, DC, USA, 2014; Volume 9069, p. 90690E.

5. Cai, Y.; Lu, W.; Wang, L.; Xing, W. Cloud computing research analysis using bibliometric method. Int. J. Softw. Eng. Knowl. Eng. 2015, 25, 551-571. [CrossRef]

6. Xu, X.; Li, Y.; Li, T. Statistic and analysis on science and technology literature and research hot spot in field of cloud computing. J. Nanjing Univ. Posts Telecommun. 2015, 35, 1-14. [CrossRef]

7. Huang, J.Y. Patent network analysis of cloud computing by text mining. J. Technol. 2016, 31, 127-146.

8. Yu, J.; Yang, Z.; Zhu, S.; Xu, B.; Li, S.; Zhang, M. A bibliometric analysis of cloud computing technology research. In Proceedings of the 2018 IEEE 3rd Advanced Information Technology, Electronic and Automation Control Conference, IAEAC 2018, Chongqing, China, 12-14 October 2018; pp. 2353-2358.

9. Sudolska, A.; Lis, A.; Błaś, R. Cloud computing research profiling: Mapping scholarly community and identifying thematic boundaries of the field. Soc. Sci. 2019, 8, 112. [CrossRef] 
10. Bharati, V.K.; Singh, M.P. Rejuvenating libraries from the cloud: A bibliometric analysis of cloud computing. Libr. Philos. Pract. 2019, 2552, 1-12.

11. Milian, E.Z.; Spinola, M.M.; Carvalho, M.M. Risks and uncertainties in cloud computing: Literature review, trends and gaps. IEEE Lat. Am. Trans. 2017, 15, 349-357. [CrossRef]

12. Garg, D.; Sidhu, J.; Rani, S. Emerging trends in cloud computing security: A bibliometric analyses. IET Softw. 2019, 13, 223-231. [CrossRef]

13. Narkhede, B.E.; Raut, R.D.; Narwane, V.S.; Gardas, B.B. Cloud computing in healthcare-A vision, challenges and future directions. Int. J. Bus. Inf. Syst. 2020, 34, 1-39. [CrossRef]

14. Giacobbe, M.; Fazio, M.; Celesti, A.; Abbate, T.; Villari, M. A scientometric analysis of cloud computing and QoE literature to design a cloud platform of experience for digital business. Commun. Comput. Inf. Sci. 2016, 567, 276-288. [CrossRef]

15. Aghaei Chadegani, A.; Salehi, H.; Yunus, M.M.; Farhadi, H.; Fooladi, M.; Farhadi, M.; Ale Ebrahim, N. A comparison between two main academic literature collections: Web of science and scopus databases. Asian Soc. Sci. 2013, 9, 18-26. [CrossRef]

16. Schotten, M.; El Aisati, M.; Meester, W.J.N.; Steiginga, S.; Ross, C.A. A brief history of Scopus: The world's largest abstract and citation database of scientific literature. In Research Analytics: Boosting University Productivity and Competitiveness through Scientometrics; Cantú-Ortiz, F.J., Ed.; Auerbach Publications: New York, NY, USA, 2017; pp. 31-58.

17. Zhu, J.; Liu, W. A tale of two databases: The use of Web of Science and Scopus in academic papers. Scientometrics 2020, 123, 321-335. [CrossRef]

18. Tranfield, D.; Denyer, D.; Smart, P. Towards a methodology for developing evidence-informed management knowledge by means of systematic review. Br. J. Manag. 2003, 14, 207-222. [CrossRef]

19. Porter, A.L.; Kongthon, A.; Lu, J.-C.C. Research profiling: Improving the literature review. Scientometrics 2002, 53, 351-370. [CrossRef]

20. Klincewicz, K.; Żemigała, M.; Mijal, M. Bibliometria w Zarzadzaniu Technologiami i Badaniami Naukowymi; Ministerstwo Nauki i Szkolnictwa Wyższego: Warszawa, Poland, 2012.

21. Zupic, I.; Čater, T. Bibliometric methods in management and organization. Organ. Res. Methods 2015, 18, 429-472. [CrossRef]

22. Grant, M.J.; Booth, A. A typology of reviews: An analysis of 14 review types and associated methodologies. Health Info. Libr. J. 2009, 26, 91-108. [CrossRef]

23. Snyder, H. Literature review as a research methodology: An overview and guidelines. J. Bus. Res. 2019, 104, 333-339. [CrossRef]

24. Martinez, H.; Jaime, A.; Camacho, J. Relative absorptive capacity: A research profiling. Scientometrics 2012, 92, 657-674. [CrossRef]

25. Sudolska, A.; Lis, A.; Chodorek, M. Research profiling for responsible and sustainable innovations. Sustainability 2019, 11, 6553. [CrossRef]

26. He, Q. Knowledge discovery through co-word analysis. Libr. Trends 1999, 48, 133-159.

27. Börner, K.; Chen, C.; Boyack, K.W. Visualizing knowledge domains. Annu. Rev. Inf. Sci. Technol. 2003, 37, 179-255. [CrossRef]

28. Van Eck, N.J.; Waltman, L. Software survey: VOSviewer, a computer program for bibliometric mapping. Scientometrics 2010, 84, 523-538. [CrossRef] [PubMed]

29. Van Eck, N.J.; Waltman, L. VOSviewer Manual; Universiteit Leiden: Leiden, The Netherlands, 2018.

30. Donohue, J.C. Understanding Scientific Literature: A Bibliometric Approach; MIT Press: Cambridge, MA, USA, 1974; ISBN 9780262040396.

31. Guo, D.; Chen, H.; Long, R.; Lu, H.; Long, Q. A co-word analysis of organizational constraints for maintaining sustainability. Sustainability 2017, 9, 1928. [CrossRef]

32. Czakon, W. Metodyka systematycznego przegladu literatury. Przeglad Organ. 2011, 3, 57-61. [CrossRef]

33. Beloglazov, A.; Abawajy, J.; Buyya, R. Energy-aware resource allocation heuristics for efficient management of data centers for cloud computing. Futur. Gener. Comput. Syst. 2012, 28, 755-768. [CrossRef]

34. Berl, A.; Gelenbe, E.; Di Girolamo, M.; Giuliani, G.; De Meer, H.; Dang, M.Q.; Pentikousis, K. Energy-efficient cloud computing. Comput. J. 2010, 53, 1045-1051. [CrossRef]

35. Beloglazov, A.; Buyya, R.; Lee, Y.C.; Zomaya, A. A taxonomy and survey of energy-efficient data centers and cloud computing systems. Adv. Comput. 2011, 82, 47-111. [CrossRef] 
36. Lee, Y.C.; Zomaya, A.Y. Energy efficient utilization of resources in cloud computing systems. J. Supercomput. 2012, 60, 268-280. [CrossRef]

37. Miettinen, A.P.; Nurminen, J. Energy efficiency of mobile clients in cloud computing. In Proceedings of the 2nd USENIX Workshop on Hot Topics in Cloud Computing, HotCloud 2010, Boston, MA, USA, 22 June 2010; p. 156224.

38. You, C.; Huang, K.; Chae, H. Energy efficient mobile cloud computing powered by wireless energy transfer. IEEE J. Sel. Areas Commun. 2016, 34, 1757-1771. [CrossRef]

39. Mastelic, T.; Oleksiak, A.; Claussen, H.; Brandic, I.; Pierson, J.M.; Vasilakos, A.V. Cloud computing: Survey on energy efficiency. ACM Comput. Surv. 2015, 47,33. [CrossRef]

40. Hameed, A.; Khoshkbarforoushha, A.; Ranjan, R.; Jayaraman, P.P.; Kolodziej, J.; Balaji, P.; Zeadally, S.; Malluhi, Q.M.; Tziritas, N.; Vishnu, A.; et al. A survey and taxonomy on energy efficient resource allocation techniques for cloud computing systems. Computing 2016, 98, 751-774. [CrossRef]

41. Guo, S.; Xiao, B.; Yang, Y.; Yang, Y. Energy-efficient dynamic offloading and resource scheduling in mobile cloud computing. In Proceedings of the 15th Annual IEEE International Conference on Computer Communications, IEEE INFOCOM 2016, San Francisco, CA, USA, 10-14 April 2016; p. 7524497.

42. Mi, H.; Wang, H.; Yin, G.; Zhou, Y.; Shi, D.; Yuan, L. Online self-reconfiguration with performance guarantee for energy-efficient large-scale cloud computing data centers. In Proceedings of the 2010 IEEE 7th International Conference on Services Computing, SCC 2010, Miami, FL, USA, 5-10 July 2010; pp. 514-521.

43. Boru, D.; Kliazovich, D.; Granelli, F.; Bouvry, P.; Zomaya, A.Y. Energy-efficient data replication in cloud computing datacenters. Cluster Comput. 2015, 18, 385-402. [CrossRef]

44. Zhang, W.; Wen, Y.; Wu, D.O. Energy-efficient scheduling policy for collaborative execution in mobile cloud computing. In Proceedings of the IEEE INFOCOM, Turin, Italy, 14-19 April 2013; pp. 190-194.

45. Goudarzi, H.; Pedram, M. Energy-Efficient virtual machine replication and placement in a cloud computing system. In Proceedings of the 2012 IEEE 5th International Conference on Cloud Computing, CLOUD 2012, Honolulu, HI, USA, 24-29 June 2012; pp. 750-757.

46. Kaur, T.; Chana, I. Energy efficiency techniques in cloud computing: A survey and taxonomy. ACM Comput. Surv. 2015, 48. [CrossRef]

47. Li, H.; Zhu, G.; Cui, C.; Tang, H.; Dou, Y.; He, C. Energy-efficient migration and consolidation algorithm of virtual machines in data centers for cloud computing. Computing 2016, 98, 303-317. [CrossRef]

48. Van Eck, N.J.; Waltman, L. Farewell Rainbow! New Colors in VOSviewer. Available online: https: //www.cwts.nl/blog?article=n-r2s274 (accessed on 7 December 2019).

49. Kandavel, N.; Kumaravel, A. Offloading computation for efficient energy in mobile cloud computing. Int. J. Innov. Technol. Explor. Eng. 2019, 8, 4317-4320. [CrossRef]

50. Joyee De, S.; Saha, S.; Pal, A.K. Achieving energy efficiency and security in mobile cloud computing. In Proceedings of the 3rd International Conference on Cloud Computing and Services Science, Aachen, Germany, 8-10 May 2013; pp. 469-474.

51. Afianian, A.; Nobakht, S.S.; Ghaznavi-Ghoushchi, M.B. Energy-efficient secure distributed storage in mobile cloud computing. In Proceedings of the 23rd Iranian Conference on Electrical Engineering, Tehran, Iran, 10-14 May 2015; pp. 740-745.

52. Ahamed, F.; Shahrestani, S.; Javadi, B. Security aware and energy-efficient virtual machine consolidation in cloud computing systems. In Proceedings of the 15th IEEE Intl Conference on Trust, Security and Privacy in Computing and Communications, 10th IEEE Intl Conference on Big Data Science and Engineering and 14th IEEE Intl Symposium on Parallel and Distributed Processing with Applications, Tianjin, China, 23-26 August 2016; pp. 1516-1523.

53. Malekloo, M.-H.; Kara, N.; El Barachi, M. An energy efficient and SLA compliant approach for resource allocation and consolidation in cloud computing environments. Sustain. Comput. Informatics Syst. 2018, 17, 9-24. [CrossRef]

54. Su, H.; Fan, Z.; Cao, C.; Zhang, Y.; Wang, S.; Meng, X. ScholarCitation: Chinese scholar citation analysis based on ScholarSpace in the field of computer science. Front. Big Data 2019, 2, 41. [CrossRef]

55. White, K.E.; Robbins, C.; Khan, B.; Freyman, C. Science and engineering publication output trends: 2014 shows rise of developing country output while developed countries dominate highly cited publications. Natl. Cent. Sci. Eng. Stat. Infobr. 2017, 18-300, 1-7.

56. De Vries, A. Bitcoin's growing energy problem. Joule 2018, 2, 801-805. [CrossRef] 
57. Sharma, Y.; Javadi, B.; Si, W.; Sun, D. Reliability and energy efficiency in cloud computing systems: Survey and taxonomy. J. Netw. Comput. Appl. 2016, 74, 66-85. [CrossRef]

58. Sharma, Y.; Javadi, B.; Si, W. On the reliability and energy efficiency in cloud computing. Conf. Res. Pract. Inf. Technol. Ser. 2015, 163, 111-114.

59. Choudhary, A.; Rana, S.; Matahai, K.J. A critical analysis of energy efficient virtual machine placement techniques and its optimization in a cloud computing environment. Phys. Proc. 2016, 78, 132-138. [CrossRef]

60. Atiewi, S.; Yussof, S.; Ezanee, M.; Almiani, M. A review energy-efficient task scheduling algorithms in cloud computing. In Proceedings of the 2016 IEEE Long Island Systems, Applications and Technology Conference, LISAT 2016, Farmingdale, NY, USA, 29 April 2016.

61. Usman, M.J.; Ismail, A.S.; Abdul-Salaam, G.; Chizari, H.; Kaiwartya, O.; Gital, A.Y.; Abdullahi, M.; Aliyu, A.; Dishing, S.I. Energy-Efficient nature-inspired techniques in cloud computing datacenters. Telecommun. Syst. 2019, 71, 275-302. [CrossRef]

62. Mondal, J.; Pradeep, K.V.; Vijayakumar, V. A review on energy efficient job scheduling algorithms in green cloud computing. Asian J. Pharm. Clin. Res. 2017, 10, 453-456. [CrossRef]

63. Liu, Q.; Ma, Y.; Alhussein, M.; Zhang, Y.; Peng, L. Green data center with IoT sensing and cloud-assisted smart temperature control system. Comput. Netw. 2016, 101, 104-112. [CrossRef]

64. Gill, S.S.; Tuli, S.; Xu, M.; Singh, I.; Singh, K.V.; Lindsay, D.; Tuli, S.; Smirnova, D.; Singh, M.; Jain, U.; et al. Transformative effects of IoT, blockchain and artificial intelligence on cloud computing: Evolution, vision, trends and open challenges. Internet Things 2019, 8, 100118. [CrossRef]

65. Antonakakis, M.; April, T.; Bailey, M.; Bernhard, M.; Bursztein, E.; Cochran, J.; Durumeric, Z.; Halderman, J.A.; Invernizzi, L.; Kallitsis, M.; et al. Understanding the Mirai botnet. In Proceedings of the 26th USENIX Security Symposium; USENIX Association, Vancouver, BC, Canada, 16-18 August 2017; pp. 1093-1110.

66. Antonakaki, D.; Papachristos, C.; Ioannidis, S. (Eds.) EUNITY Project Deliverable D2.2: Workshop 2 Proceedings: Cybersecurity and Privacy Dialogue between Europe and Japan; EU Cooperation and International Dialogues in Cybersecurity and Privacy Research and Innovation: Brussels, Belgium, 2019.

67. Antonakaki, D.; Papachristos, C.; Ioannidis, S. (Eds.) EUNITY Project Deliverable D2.3: Workshop 1 Proceedings: Cybersecurity and Privacy Dialogue between Europe and Japan; EU Cooperation and International Dialogues in Cybersecurity and Privacy Research and Innovation: Brussels, Belgium, 2018.

68. Itani, W.; Kayssi, A.; Chehab, A. Energy-efficient incremental integrity for securing storage in mobile cloud computing. In Proceedings of the 2010 International Conference on Energy Aware Computing, ICEAC 2010, Cairo, Egypt, 16-18 December 2010; p. 5702296.

69. Mollah, M.B.; Azad, M.A.K.; Vasilakos, A. Security and privacy challenges in mobile cloud computing: Survey and way ahead. J. Netw. Comput. Appl. 2017, 84, 38-54. [CrossRef]

70. Stergiou, C.; Psannis, K.E.; Gupta, B.B.; Ishibashi, Y. Security, privacy \& efficiency of sustainable cloud computing for Big Data \& IoT. Sustain. Comput. Inform. Syst. 2018, 19, 174-184. [CrossRef]

71. Radu, L.D. Determinants of green ICT adoption in organizations: A theoretical perspective. Sustainability 2016, 8, 731. [CrossRef]

72. Carberry, E.J.; Bharati, P.; Levy, D.L.; Chaudhury, A. Social movements as catalysts for corporate social innovation: Environmental activism and the adoption of green information systems. Bus. Soc. 2019, 58, 1083-1127. [CrossRef]

(C) 2020 by the authors. Licensee MDPI, Basel, Switzerland. This article is an open access article distributed under the terms and conditions of the Creative Commons Attribution (CC BY) license (http://creativecommons.org/licenses/by/4.0/). 